\title{
Translation and Validation of the Portuguese Version of the Surprise Question
}

\author{
Paulo Faria de Sousa, $\mathrm{MD}^{1,2}$ and Miguel Julião, $\mathrm{MD}, \mathrm{MSc}, \mathrm{PhD}^{3}$
}

\section{Dear Editor:}

The need to identify patients with palliative care needs has resulted in the development of several tools. ${ }^{1}$ The surprise question (SQ) Would you be surprised if this patient died in the next year? ${ }^{2}$ has been tested in several contexts for this purpose throughout the years, leading to a fairly consistent identification of populations suffering from advanced and life-limiting illnesses, such as cancer, ${ }^{2}$ chronic kidney diseases, ${ }^{3}$ among others. ${ }^{4}$

Portugal is undergoing a reform and expansion of its national palliative care network, and the need to use simple and effective instruments like the SQ is increasing, both clinically and in the research field. To date, no Portuguese SQ version was available. For these reasons, we conducted a methodological study with the aim of performing the translation and validation of the Portuguese version of the SQ.

We began by doing the forward linguistic translation into European Portuguese by two translators (one nonclinician and the other clinician), native in Portuguese and fluent in English. Both translators were naive for the concepts under study. Differences between the two translations were detected on words such as "surprise," "patient," "died," and "next year." After agreement upon the best synonyms to use (P.S. and M.J.), a consensus version was created: Ficaria surpreendido se este doente morresse durante o próximo ano? To further strengthen the process, a blind back translation was made by an external bilingual translator and $100 \%$ agreement was obtained on the semantic analysis. The consensus version was sent to experts committee review (two doctors, one nurse, and one psychologist with primary care and palliative medicine advanced training) to assess face validity on conceptual, semantic, experiential, and content equivalence. After discussion, no changes were made and all the committee members robustly agreed on the final Portu- guese SQ version as follows: Ficaria surpreendido se este doente morresse durante o próximo ano?

After the translation and validation of the Portuguese SQ version, a new tool is now available to assess Portuguese patients eligible for palliative care. Future studies using the Portuguese SQ version can now take place with clinicians and patients, assessing its applicability and acceptability.

\section{References}

1. Maas EAT, Murray SA, Engels Y, Campbell C: What tools are available to identify patients with palliative care needs in primary care: A systematic literature review and survey of European practice. BMJ Support Palliat Care 2013;3:444-451.

2. Moroni M, Zocchi D, Bolognesi D, et al.: The "surprise", question in advanced cancer patients: A prospective study among general practitioners. Palliat Med 2014;28:959-964.

3. Moss AH, Ganjoo J, Sharma S, et al.: Utility of the "Surprise" question to identify dialysis patients with high mortality. Clin J Am Soc Nephrol 2008;3:1379-1384.

4. Gomez-Batiste X, Martinez-Munoz M, Blay C, et al.: Utility of the NECPAL CCOMS-ICO $(\mathrm{C})$ tool and the Surprise Question as screening tools for early palliative care and to predict mortality in patients with advanced chronic conditions: A cohort study. Palliat Med 2016; [Epub ahead of print; DOI: 10.1177/ 026921631666647].

Address correspondence to: Paulo Faria de Sousa, MD Unidade de Saúde Familiar AlphaMouro Av. Infante D. Henrique, 39-41, Piso 1, 2635-364 Rio de Mouro Portugal

E-mail: paulo.faria.sousa@gmail.com

\footnotetext{
${ }^{1}$ Unidade de Saúde Familiar AlphaMouro, Rio de Mouro, Portugal.

${ }^{2}$ Faculty of Medicine, University of Lisbon, Lisbon, Portugal.

${ }^{3}$ School of Medicine, University of Minho, Life and Health Sciences Research Institute (ICVS), Braga, Portugal.
} 